them during their sexual season. These arenas are evidence of convergent evolution.

In bower-birds a simple display came first. The ontogeny of the satin bower-bird's display can be seen in the increasing elaboration of its ritual as the individual gains in maturity and experience. By scattering a few fragments of blue glass under a wild fig tree on which the young were feeding, Marshall was able to stimulate them to fly down, to snatch up the glass, and to display even without a bower. Later the young green males would build a simple platform of a few twigs and display there with the accumulated coloured objects ; generally these would be stolen from neighbouring adult blue males and carried off to their bowers. As the young green birds grow older, they make low-walled avenue bowers, but before they themselves change colour at the age of five or six years to a mature blue-black they are capable of building a bower as elaborate as that of their elders.
Marshall sees the bower as a result of a displaced nesting-drive. The male, which takes no part in nest building, erects a structure on his display arena. The bower-birds have developed this display tendencyknown in various other species---to an extraordinary degree ; some species select coloured objects in the image of male rivals and use them violently in a noisy display which attracts the female and deters interlopers. Strong intraspecific competition has been a powerful factor in the evolution of bower-bird display.

Much has been written about the supposed intelligence of bower-birds, but there is evidence that they are no more intelligent than other highly developed passerine species. Much, too, has been written of their alleged conscious artistry; but their choice is essentially mechanical and unvarying. A species that uses greenish-yellow, for example, will never select green. None, so far as is known, ever varies its colour scheme.

\title{
RADAR ECHOES FROM THE AURORA AT I,300 MC./S.
}

\author{
By Dr. E. EASTWOOD, G. A. ISTED and J. D. BELL \\ Marconi's Wireless Telegraph Co., Ltd., Great Baddow, Essex
}

\begin{abstract}
$\mathrm{D}^{\mathrm{t}}$

Radar frequency
Pulse recurrence frequency
Pulse-length
Power
Aerial rotation
Horizontal beam-width
Vertical polar diagram
Polarization
Aerial gain
\end{abstract}
URING the course of radar experiments directed primarily to the study of the movements of 'angels' and various types of cloud forms, we have recorded some very interesting radar echoes from the aurora at a wave-length of $23 \mathrm{~cm}$. The observations have been made with a high-power $L$-band radar possessing the following system parameters :

$$
\begin{aligned}
& =1,306 \mathrm{Mc} . / \mathrm{s} . \\
& =100 \mathrm{p} . \mathrm{p} . \mathrm{s} . \\
& =5 \mu \mathrm{sec} . \\
& =2 \mathrm{MW} . \\
& =4 \mathrm{r.p} . \mathrm{m} . \\
& =0.7^{\circ} \text { (between half power points) } \\
& \left.=\text { cosec. } .^{2} \text { (lobe maximum at } 1 \cdot 6^{\circ}\right) \\
& =\text { horizontal } \\
& =10,000
\end{aligned}
$$

During the two years of observations with this equipment the following three sets of auroral echo records have been secured :

$$
\begin{array}{lc}
\text { Date } & \text { Duration of radar aurora } \\
\text { July 15, 1959 } & 15.50-17.15 \text { U.T. } \\
\text { April 1, 1980 } & 14.00-17.50 \text { U.T. } \\
\text { October 6, 1960 } & 16.50-18.25 \text { U.T. }
\end{array}
$$

The appearance of the radar aurora as seen on the plan position indicator at 17.43 U.T. of October 6 1960, is shown in Fig. 1. This record shows those essential features of the fully developed aurora which have been substantially reproduced on the occasions listed above, namely, the presence of two auroral ares, the ranges of the extremities of which lie between $600 \mathrm{~km}$. and $1,200 \mathrm{~km}$., the azimuthal position of the arcs and their lateral extent. The rapidly changing form of the aurora is rendered vividly apparent by the method of time-lapse photography whereby photographs of the plan position indicator are taken so that successive scans of the aerial occupy consecutive frames of a ciné film. Projection of such a film through an ordinary ciné projector running at 16 frames per sec. gives a time compression factor of 240 ; this technique permits the movements of the auroral forms to be clearly observed and measured.
The real or apparent motions of the scattering electron clouds within the auroral ares will be discussed elsewhere; but it is of interest to note that there is a marked tendency for the western limb to show a preponderance of 'receding' clouds.

An interesting feature of the observations of July 15, 1959, was that this auroral record followed a series of plan position indicator photographs taken at sunrise (03.59 U.T.) on the morning of July 14 when the disturbed state of the Sun was made manifest by the greatly enhanced solar noise signal received by the radar. These two direct observations, on the one radar equipment, of the solar disturbance and the subsequent aurora set a time-interval between the two events of $36 \mathrm{hr}$.; this figure has to be increased to $36 \frac{1}{2} \mathrm{hr}$. when the time of first onset of the solar disturbance, as observed by S.I.D.s in the eastern hemisphere, is allowed for. (Solar flare, importance $3+, 03.25$ U.T., 14.7.59.) Such a timeinterval would correspond to an average velocity of the particles emitted from the Sun of the order of $1,133 \mathrm{~km}$. $/ \mathrm{sec}$.

Examination of the advices of magnetic data issued by the Eskdalemuir Observatory shows that

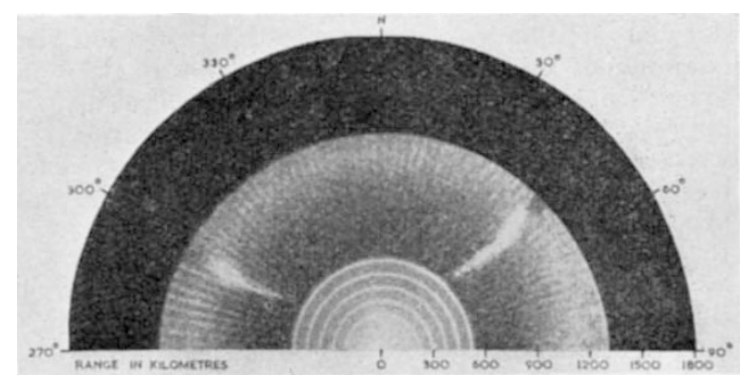

Fig. 1. Radar echoes from the aurora on $1,300 \mathrm{Mc} / \mathrm{s} .(17 \cdot 43 \mathrm{hr}$, October 6,1960 ) 
the usual disturbance to the $H$-field there is of the order of 100-300 $\gamma$. For April 1, 1960, however, disturbances of $2,600 \gamma$ were recorded, while the magnetic storm of July 15, 1959, was even more violent in that disturbances of $4,100 \gamma$ were observed. Survey of the records since 1949 shows that there have been only 21 occasions during the past 11 years when the disturbance in the $H$-field has exceeded $1,000 \gamma$; if these events are listed in order of diminishing intensity, then the first six entries appear as follows :

List OF MAGNeTiC Disturbances (1949-60)

\begin{tabular}{|c|c|c|c|c|}
\hline Order & Year & Date & $\begin{array}{l}H \text {-disturb- } \\
\text { ance }(\gamma)\end{array}$ & $\begin{array}{l}\text { Radar aurora } \\
(1,300 \text { Mc./s. })\end{array}$ \\
\hline $\begin{array}{l}1 \\
2\end{array}$ & $\begin{array}{l}1959 \\
1958\end{array}$ & $\begin{array}{l}\text { July } 15 \\
\text { February } 11\end{array}$ & $\begin{array}{l}4,103 \\
2,762\end{array}$ & $\begin{array}{l}\text { Observed } \\
\text { Equipment not } \\
\text { in use }\end{array}$ \\
\hline $\begin{array}{l}3 \\
4\end{array}$ & $\begin{array}{l}1960 \\
1957\end{array}$ & $\begin{array}{l}\text { April } 1 \\
\text { January } 22\end{array}$ & $\begin{array}{l}2,592 \\
2,340\end{array}$ & $\begin{array}{l}\text { Observed } \\
\text { Equipment not } \\
\text { in use }\end{array}$ \\
\hline 5 & 1957 & September 4 & 2,300 & Equipment not \\
\hline 6 & 1960 & October 6 & 2,280 & Observed \\
\hline
\end{tabular}

It is clear from this correlation between the occurrence of the radar auroræ reported in this article and the intensity of the magnetic disturbances as recorded at Eskdalemuir that only the more violent solar eruptions are likely to produce disturbances in the Earth's ionosphere of intensity sufficient to yield auroral echoes on a radar operating at so high a frequency as $1,300 \mathrm{Mc} . / \mathrm{s}$.; such events are likely to be comparatively rare.

The nature and spatial distribution of the radar echoes obtained at very high frequency during auroral activity have been studied by a number of workers; these investigations have clearly established the existence of aspect sensitivity in auroral radio reflexions. Chapman ${ }^{1}$ has described the geometry of the reflexion process on the assumption that the reflecting 'rays' of the aurora are lying along the lines of force of the geomagnetic field, this latter being represented by the field of the equivalent centred dipole. Booker ${ }^{2}$ has sought to reduce the degree of aspect sensitivity suggested by Chapman by a theory of scattering which postulates nonisotropic irregularities in the density of electrons in the aurora, such regions having their major axes parallel to the Earth's field. Booker ${ }^{3}$ has applied his theory to the scattering of radio waves at frequencies up to $100 \mathrm{Mc} . / \mathrm{s}$, and in his treatment he assumes that the electron density in the aurora is increased only by a factor 10 over that normally obtaining in the $E$-layer. Fricker et al. ${ }^{4}$ have obtained substantial agreement between the positions of auroral echoes observed at $400 \mathrm{Mc} / \mathrm{s}$. and the areas of reflexion derived by approximate specular reflexion from columns of electrons lying along the Earth's field lines; in this analysis the actual Earth's field appropriate to the location of their radar stations was employed as distinct from the field inferred from the equivalent dipole approximation. The same process of specular reflexion was suggested by Peterson $^{5}$ to be the explanation of certain middle latitude echoes of auroral type, and Watkins ${ }^{6}$ has shown that specular reflexion is closely obeyed in the case of the auroral echoes obtained at Jodrell Bank on wave-lengths of $4 \mathrm{~m}$. and $8 \mathrm{~m}$. Similar results have been reported by Harrison ${ }^{7}$ from the International Geophysical Year auroral studies at Halley Bay.

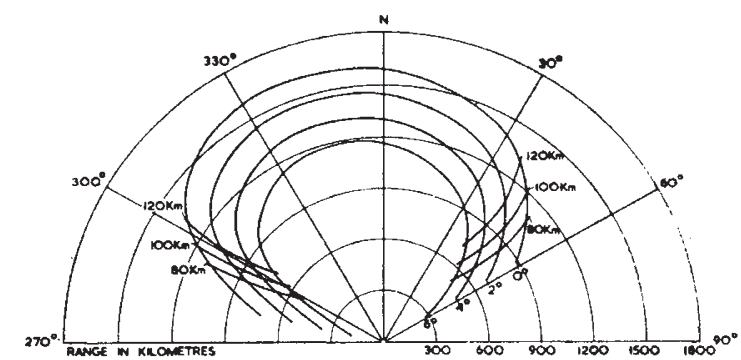

Fig. 2. Polar map for Bushy Hill, Essex, showing loci of feet of perpendiculars on the lines of force of the Earth's magnetic fleld

It is the high resolving power in both range and azimuth of the $1,300 \mathrm{Mc} / \mathrm{s}$. redar equipment that has permitted the form of the aurora to be photographed with the precision shown in Fig. 1. The detail contained in this record allows the theory of radio reflexion from field-aligned regions of electron concentration to be tested and the stringency of the specular reflexion condition assessed in the case of $a$ wave-length of $23 \mathrm{~cm}$.

In Fig. 2 are shown the loci of the feet of the perpendiculars drawn from the radar site at Bushy Hill, Essex, to the lines of force of the Earth's field; each curve corresponds to a given angle of elevation of the rays from the radar. The magnetic data from which these curves have been calculated was taken from the Admiralty charts of isogonics and isoclinics (January 1960). Also included in Fig. 2 are the curves of constant height corrected for atmospheric refraction.

It will be seon that the area of Fig. 2 included between the $80 \mathrm{~km}$. and $100 \mathrm{~km}$. height curves and lying between the $0^{\circ}$ and $6^{\circ}$ elevation loci corresponds very closely indeed to the auroral arcs of Fig. 1. Now the beam-width of the radar in the horizontal plane is $0.7^{\circ}$ while the angle subtended by a tangential element of the auroral arc at $1,000 \mathrm{~km}$. is $5^{\circ}$. It is clear, therefore, that the azimuthal extent of the auroral form of Fig. I is not attributable to the beam-width of the radar. The azimuthal location of a height curve as plotted on Fig. 2 is quite sensitive to the height parameter and so a possible interpretation of Fig. 1 in the light of Fig. 2 would be that the auroral reflexions commence in the region of the $80-\mathrm{km}$. level of the ionosphere and extend upwards to an approximate height of $105 \mathrm{~km}$. Alternatively, the azimuthal spread of the auroral arc could be regarded as arising from rays incident, at angles between $90 \pm \frac{1}{2}^{\circ}$ on the auroral columns of ionization located at a height of $90 \mathrm{~km}$. It is probable that both the aspect and altitude effects play their parts in forming the auroral patterns of Fig. 1, but the present microwave experiments clearly show that the departure from the $90^{\circ}$ reflexion condition is less than $\pm \frac{1}{2}^{\circ}$, and that the region of the ionosphere where the auroral reflexions take place is of the order of $20 \mathrm{~km}$. thick.

The mean height of the auroral layer as deduced from Fig. 1 by measurement of the azimuthal spread of the two auroral arcs, that is, $90 \mathrm{~km}$., is lower than the value suggested by other workers operating at much lower radio frequencies. The evidence given above suggests that an auroral disturbance of sufficient intensity to be observed at $1,300 \mathrm{Mc} / \mathrm{s}$. will only occur as an aftermath of a very vigorous solar upheaval and in association with extreme magnetic storms. In these circumstances it might be expected 
that the solar emission would contain a proportion of more energetic primary particles capable of producing ionization at lower levels of the ionosphere and also of yielding auroral displays at lower latitudes. This southward movement of the aurora during the growth of intense magnetic storms has been discussed by Störmer ${ }^{8}$ and has received confirmation in recent International Geophysical Year work'. It will be noted, however, that the kinetic energy of the solar particles at the moment of penetration into the Earth's atmosphere, if taken as that corresponding to the average velocity of transit from the Sun to the Earth, that is, $1,133 \mathrm{~km}$./sec. as given above, would scarcely seem adequate to produce the observed microwave auroral effects at so low an altitude as $80-100 \mathrm{~km}$.; it is probable that account must also be trken of the flux density of the incident particles.

The fact that the aurora of Fig. 1 was not observed in a northerly direction from the radar is a consequence of the shape of the vertical radiation diagram of the aerial, which extends from $0.2^{\circ}$ to $6^{\circ}$, these elevations corresponding to 10 decibels of power reduction relative to that of the lobe maximum located at $1 \cdot 6^{\circ}$. This figure of $1 \cdot 6^{\circ}$, when associated with the observed range of $1,000 \mathrm{~km}$. for the position of the echo of maximum amplitude, gives a height of $98 \mathrm{~km}$. for this particular reflexion point.

The signal/noise ratio measured for this echo was $1 \cdot 3 / 1$; since the receiver noise-level was $4 \times 10^{-15}$ watt, it may be deduced that the equivalent radar cross-section of a region of the aurora which yields a single pulse point on the plan position indicator is
$1 \cdot 4$ sq. $\mathrm{m}$. By making reasonable assumptions as to the volume of the ionosphere contributing to this signal the echoing area per unit volume of the auroral scattering region may be estimated as of the order of $10^{-9} \mathrm{~m} \cdot .^{-1}$.

If incoherent scattering by electrons is responsible for this reflexion of microwave energy, then, taking the Thomson cross-section of a single electron as of the order of $10^{-80} \mathrm{~m}^{2}{ }^{2}$ would lead to a density of electrons of $10^{14}$ per c.c. On the other hand the electron density corresponding to normal critical reflexion for a frequency of $1,300 \mathrm{Mc} / \mathrm{s}$. Would be $2 \times 10^{10}$ electrons per c.c. It seems clear that neither of these mechanisms can be responsible for the auroræ observed at $1,306 \mathrm{Mc} / \mathrm{s}$. and that a theory of scattering such as has been developed by Booker (loc. cit.) must be applied.

We wish to thank our colleagues of the Radar and Photographic Groups for their assistance with the observational programme and the Director of Eskdalemuir Observatory for supplying the magnetic data.

${ }^{1}$ Chapman, S., J. Atmos. Terr. Phys., 3, 1 (1952).

${ }^{2}$ Booker, H. G., J. Atmo8. Terr. Phys., 8, 204 (1956).

${ }^{3}$ Booker, H. G. "Physics of the Upper Atmosphere", ed. Ratcliffe, J. A. (Academic Press, London, 1960).

4 Fricker, S. J., Ingalls, R. P., Stone, M. L., and Wang, S. C., J. Grophys. Res., 62, 527 (1957).

'Peterson, A. M., Villard, O. G., Leadabrand, R. L., and Gallagher, P. B., J. Geophys. Res., 60, 497 (1955).

6 Watkins, C. D., J. Atmos. Terr. Phys., 19, 1 (1960).

'Harrison, D. P., Proc. Roy. Soc., A, 258, 229 (1960)

- Störmer, C. "The Polar Aurora" (Oxford, 1955).

- Obayashi, T., and Hakura, Y., "Report of Yonosphere Research in Japan", 14, 1 (1960).

\title{
A VERSATILE METHOD FOR SHORT-TERM SPECTRUM ANALYSIS IN 'REAL-TIME'
}

\author{
By J. S. GILL
}

Joint Speech Research Unit, Eastcote, Middlesex

\begin{abstract}
$\mathrm{T}$ HE variations with time of the short-term energy spectrum of signals such as speech, music, singing, etc., can be measured with a bank of electrical band-pass filters and rectifiers. This leads to the type of display in three dimensions (time, frequency, intensity) commonly known as a sound spectrogram. Spectrographic patterns have proved of great value in the study of complicated audio frequency signals, especially human speech. However, this method becomes impractical when large numbers of filters are required. For example, at least 160 filters would be needed to provide a reasonable display when analysing a band $4 \mathrm{kc}$. $/ \mathrm{s}$. wide with filters $50 \mathrm{c} . / \mathrm{s}$. wide. A choice of analysis band-width is also often required, and this is particularly difficult to arrange on a large filter-bank.

The analysis can be performed in a much more economical and flexible manner by recording the signal and then analysing by repeatedly playing this recording through a single filter. The signal is swept slowly across the pass-band of this filter by means of a frequency-changing process'. (Any filter 'remembers' its immediate past history, and so it is not possible to analyse merely by sweeping the single filter rapidly across the frequency band occupied by the original signal ${ }^{2}$.) The output of this filter is recorded on a surface, usually a sheet of
\end{abstract}

electro-sensitive paper, which rotates synchronously with the recorded signal, thus producing a sound spectrogram. The time required for a complete analysis is at least :

$$
T=t+\frac{N t}{k}
$$

where $T=$ total time required, $t=$ original duration of recorded signal, $N=$ required number of separate analyses, $k=$ play-back speed/recording speed. In most existing instruments of this type $T / t$ is about 100.

There are many calls, particularly in the study of speech, for a versatile spectrum analyser the output of which unfolds as the speech proceeds in time, that is, operates in 'real-time'. Although a filterbank can be used for this purpose, detailed analysis by this method is rather impractical, dus to the large number of filters that are needed. The single filter method outlined above cannot provide 'real-time' operation, however large $k$ may be, because recording and analysis do not proceed simultaneously. In the method to be described these two processes of recording and analysis are interleaved, as shown in Fig. 1, to enable a single anslysis filter to be used for determination, in 'real-time', of the short-term spectral properties of a signal. 